\title{
Teaching Journeys of Engineering Faculty: Stories of Transition
}

\section{Ms. Sandra Bird, University of Georgia}

Ms. Bird is an environmental engineer retired from the U.S. Environmental Protection Agency. She is currently pursuing a Ph.D. in engineering at the University of Georgia, College of Engineering.

\section{Dr. Nadia N. Kellam, University of Georgia}

Nadia Kellam is an Associate Professor in the College of Engineering at the University of Georgia where she is co-director of the interdisciplinary CLUSTER research group. Dr. Kellam is interested in understanding how engineering students develop their professional identity; her research focuses specifically on creativity, interdisciplinarity, and the role of emotion in cognition. She created the synthesis and design studios in the environmental engineering program and is currently developing the professional and design spines for the upcoming mechanical engineering program. She is also interested in faculty development and recently co-organized the NSF-sponsored PEER workshop for tenure-track engineering education research faculty. 


\title{
Teaching Journeys of Engineering Faculty: Stories of Transition
}

\begin{abstract}
The need for more engineers with a broader world view has led to a call for a change in teaching strategies in engineering. Since developing "evidence-based" teaching innovations has not been enough to effect pervasive change in teaching practices in engineering schools, a need to understand how these innovations are adopted is broadly acknowledged. To aid in this understanding, we interviewed 3 individuals to see how they perceived their teaching journey and why they moved from teaching how they were taught to adopting student-centered practices. A narrative framework was used in the development of the interview questions and analysis of the responses. The three individuals described their initial approach to teaching with respect to how they were taught. Mentors and colleagues were important along the change path to these individuals. Lack of time and a cultural context that did not value teaching were perceived as the barriers to changing teaching practices.
\end{abstract}

\section{Introduction}

Engineers must deal with increasingly multi-layered, highly complex, and urgent problems with no obvious optimal solution. Reports such as The Engineer of 2020: Visions of Engineering in the $21^{\text {st }}$ Century ${ }^{1}$ describe a profession needing more diverse individuals with a broader world view and a need for engineering schools to graduate $21^{\text {st }}$ century thinkers. In order to change the characteristics of graduates to being more $21^{\text {st }}$ century thinkers, there is a recognized need for a change in teaching strategies. ${ }^{2}$ This has paralleled the call for a transformational change in the broader science, technology, engineering, and math (STEM) education community ${ }^{3}$ and has resulted in significant resources by both government and corporate entities to improve teaching and learning in the STEM disciplines. ${ }^{4}$ Since focusing on developing evidence-based teaching innovations has not been enough to affect pervasive change in teaching practices in engineering schools, the emphasis by organizations including the National Science Foundation and the National Academy of Engineering has shifted to developing an understanding of the extent of the adoption of innovations $^{5-12}$.

In university engineering departments, individual faculty members are typically responsible for classroom practices and individual course design ${ }^{5}$ while departmental committees composed of groups of faculty are responsible for curricular development. Froyd ${ }^{5}$ describes the pervasive classroom practice in engineering departments as lecture-based and summarily characterizes the practice as "teaching as you have been taught." In this system, individual faculty members are primarily responsible for changes in practice and to implement change they must move past the classroom culture in which they developed and have continued to practice for many years.

The reward structure in research universities does not support extensive faculty focus on teaching. Promotions and tenure still rest primarily on achievements by faculty in producing scholarly publications and obtaining grants. Still some faculty members pursue teaching with enthusiasm and commit the time and energy to change their teaching practices and innovate in the classroom. Roger's ${ }^{13}$ seminal work on the diffusion of innovations serves as the framework for understanding the adoption of teaching innovations by engineering educators. This work 
stresses the importance of the strength and structure of communication networks between individuals. The adoption of innovations is rooted in the concept of social learning. ${ }^{14}$ Individuals learn by observational modeling, i.e. one observes another's behavior and does something similar. This observational modeling is not direct mimicry but rather the individual takes the essential elements of the observed behavior and performs a similar behavior.

This paper explores the process by which faculty successfully transition from a traditional teacher-centered lecture style to a learner-centered inquiry-based style of teaching as illustrated in Figure 1. The study used an in-depth interview approach with 3 exemplar faculty to elicit the stories of how they transformed their teaching style. Thematic narrative analysis was used to analyze transcriptions of open-ended interviews with these engineering educators about their personal teaching narratives. This study sought to identify how these individuals described their transition, the barriers they faced, their strategies for overcoming the barriers, and their motivation for persisting with the goal of identifying the personal and contextual factors revealed through their narrative that account for their success in making their transition.

Figure 1. Stages in the evolution of teaching styles
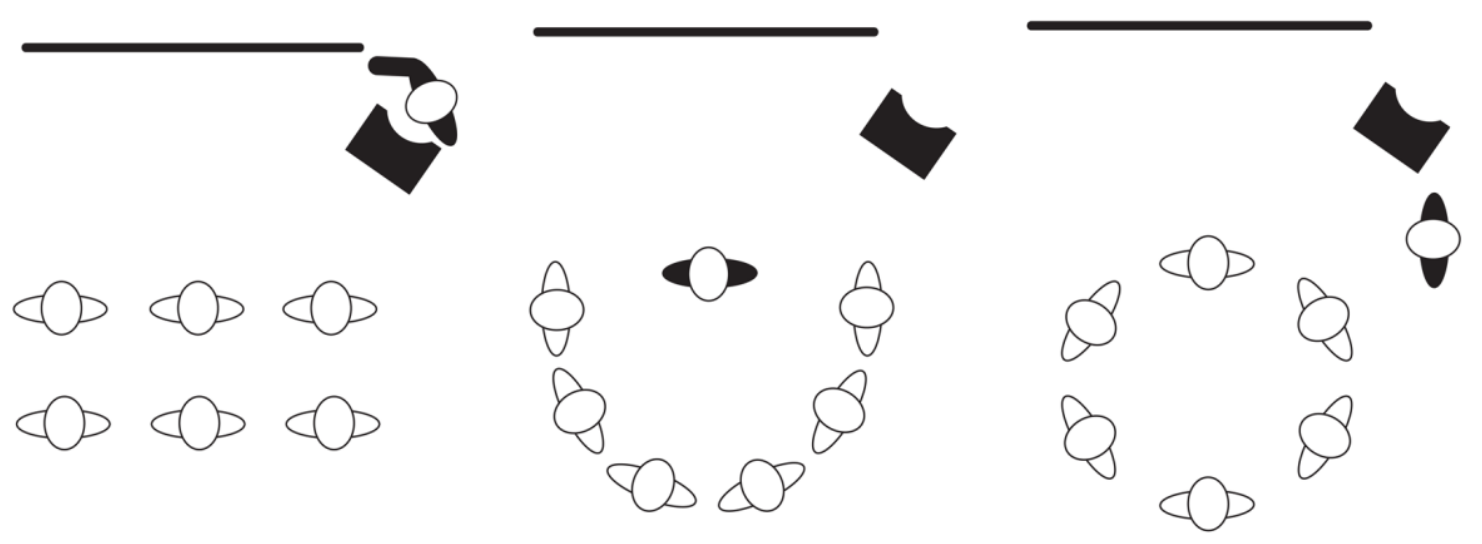

\section{Methodology}

Confidential semi-structured interviews using open-ended questions were conducted with three engineering educators who have evolved their teaching styles and adopted active learning strategies in the classroom. Participants were also asked to provide any artifacts that might provide insights into their teaching style and philosophy. As a result of this request, one of the participants provided a teaching dossier he developed to support his application for tenure based on excellence in teaching. All three of these individuals are faculty at R1 institutions and have received recognition for their innovative teaching in terms of awards and media attention. Pseudonyms have been assigned to protect confidentiality. The three individuals are at distinct career stages - an early-career assistant professor, a mid-career associate professor, and a latecareer full professor. Pseudonyms are prefaced with e, $\mathrm{m}$, and 1 respectively to indicate early-, mid-, and late- career stages. The questions in the interview were designed to elicit the stories of how they came to adopt and evolve their teaching and to understand the participant's perception of their teaching journey. The transition of teaching styles is not a single step 
adoption of an innovation and takes place over an extended period of time. Since narrative is the way humans understand the world, and stories organize life events in time, the teaching transitions lend themselves to investigation through an understand of individual narratives. Through the personal narrative, the life as told, the researcher gains insight into the life as experienced. ${ }^{15}$ The interview transcripts were analyzed in two ways. The arc of the individual narratives was summarized from the interview transcripts. In addition, the basic units of narrative as described by Labov and Waletzky ${ }^{16}$ were used to analyze the content across the different individual narratives. The structural narrative elements were used to identify themes appearing across the separate narratives.

\section{Results}

The themes reported below were identified from three o Labovian narrative elements identified within the transcripts: orientation, complicating factors, and evaluation. The Journey Begins theme arose from the orientation stage of the narratives. Prompting Change and Difficulties on the Path came from the complicating factors identified in the narratives. Mixed Messages was identified in the evaluation phase of the narrative.

\section{The Journey Begins}

While all three of the participants are award-winning instructors, they began their teaching journeys in different times and different places. All describe their initial approach to teaching with respect to how they were taught. In his teaching philosophy prepared as part of his tenure package Dr. Donaldson ${ }_{m}$ sums this up "We as engineering educators are not provided with formal training in teaching courses. Many of our teaching philosophies and techniques come from our past experiences."

Dr. Kelly $y_{1}$ describes himself as having come from a system that is "European and where there was less emphasis on the practical part and more emphasis on the theory." He describes the first class he taught after finishing his undergraduate degree "I come to class with a chalk and board, go through the various points that are important and I will entertain questions as I went along..... it was normal, that's how I had been taught." When describing his initial experience teaching, he explains, "my measure of success, well I delivered the material, and the students took the test, and if they don't perform very well you know then maybe they are poor students."

Dr. Donaldson $\mathrm{m}_{\mathrm{m}}$ also started his initial teaching by thinking about his instructors: "which professors did I think were good? What was it they did that I really liked?" One professor he had "knew everyone's name in class and during a 1 1 $1 / 2$ hour class period called on every single student in that class with a question." Reflecting on this "although at the time I did not like being asked questions ...I realized that actually one I paid attention in his class and two it gave me confidence by answering the question. Like wow I do kind of know this information and I felt I just like learned it a little bit better." He also reflected on the professors he didn't think were so good "...but they would just be up there and they would just go nonstop for an hour lecturing on the board, rarely turning their head back toward the class. You know we could have all exited the class..." Dr. Donaldson $\mathrm{m}_{\mathrm{m}}$ had instructors who created an active learning classroom environment and others who stayed in the straight lecture model. He was able to see the difference in the effect of these different styles in his own development as a student and chose 
the one from which he personally benefited the most. Dr. Donaldson ${ }_{m}$ did have the opportunity to participate in a teaching institute (a program aimed at university faculty) while in graduate school.

Dr. Jackson ${ }_{\mathrm{e}}$ 's initial teaching style was colored by her nervousness and she fell back on methods that were familiar. "At first ....I just needed my power points. I felt really nervous I just needed those.... because it's like it's only five people I mean it seems so silly to be up there lecturing to five people but at first that was how I felt the most comfortable." Classroom anxiety remains an issue for her. "Sometimes I wake up and think why did I pick an occupation where I have to get up in front of people. You know especially at the first class, I'm always so nervous, I'm like nauseous and want to throw up the first day of class. Always." This performance anxiety might also help explain her ability to enthusiastically embrace teaching methods that moved her away from the center stage.

\section{Prompting Change}

Different types of change occurred over the teaching careers of these individuals. Dr. Kelly described an incident that occurred during one of his first teaching experiences. He attributes this incident to being critical in his development as a teacher.

"I gave this test and people performed so badly and because they performed so badly the question was are they bad students. Now in this particular class there was a student that everybody was wowed by. He knew it. He had a swagger that said he was the best thing that ever happened to this department. ... If this student who everybody thinks is very smart doesn't perform well in my class well is there something wrong with the class."

At the same time Dr. Kelly $y_{1}$ was participating in a program that linked a new professor who was just beginning with a very senior faculty member noted for teaching excellence specifically as a teaching mentor. The mentor came and observed Dr. Kelly,'s class and through these interactions

"...I began to think to think about you know the measure should be how well the student's understand. In fact, it became less important that I finish the syllabus but whatever it is that I am going to work on the students will leave the class happy that they understand. So from there on I began to seek ways of getting student's attention because if I get student's attention chances that they are going to understand is improved and in a way perhaps when they do the test that understanding will show."

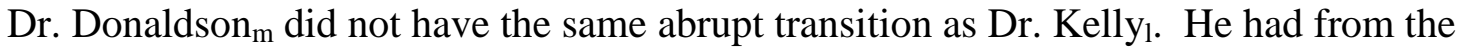
beginning of his teaching career used a more active learning style. However, he is continually trying new approaches in his class. A recent teaching adoption for him has been using a problem-based approach which he was motivated to think about because:

"....there are some courses that you teach that you're looking for ways to engage students you know like the materials class I teach it's easy to get students engaged in that type of class but in another class where I may be up at the board and doing lots of calculations and you know you can only ask so many questions and try to engage them so much and so I was looking for some other way to try to get them to kind of maybe work together as 
teams to kind of think critically and kind of think like what an engineer would have to think like outside of after they graduate."

A relationship with a colleague supported Dr. Donaldson $\mathrm{m}_{\mathrm{m}}$ in trying out problem-based learning in his classroom.

"And a colleague of mine in Colorado I shared a suite with him an office suite. He's in transportation - so a completely different unrelated civil engineering sub-discipline there. We started talking and all of the sudden we had some similar interests ....we started kind of talking about what could we do and then we kind of came up with trying to incorporate problem based learning into some classes that he and I were teaching."

For her second class, Dr. Jackson ${ }_{\mathrm{e}}$ was assigned to teach a senior design class and the first time through was with an established professor mentoring her which had a big impact on her approach to teaching these classes. "I think he mentored me extremely well ...... I don't think I would have taught it like the other class in terms of where I had a curriculum that I had to cover you know etcetera, but I would have been more interventive certainly, I wouldn't have known to sort of step back ... it became clear to me as sort of I did it that it was a real art to be able to teach them without undermining their independence of learning on their own. It's a real art." She went on to reflect: "at first I felt a little strange doing that, like okay shouldn't I be doing more but you really kind of are doing something kind of magical when you sort of let that happen."

Dr. Jackson ${ }_{\mathrm{e}}$ was motivated to change and try alternative classroom strategies both to keep her students and herself interested. When asked what triggered her to change things she talked about the student's response "And then it's mostly just that I cannot stand looking at students who look like they are bored in the classroom." She also needed classes to change to keep herself interested in teaching them: "I just need a class to be something that I can evolve over time so I have a feeling I'm going to be changing them up continuously."

\section{Difficulties on the Path}

Adopting innovative teaching practices is not easy for faculty particularly for young faculty members struggling to get tenure. Dr. Jackson ${ }_{\mathrm{e}}$ 's response to a question about barriers on adopting classroom innovation was a single word: "Time." Dr. Kelly,'s slightly expanded response to the question was: "Time is a barrier that you don't have enough of it." However, the time constraint was not the only issue. Both Dr. Kelly $y_{1}$ and Dr. Donaldson ${ }_{m}$ reported a certain disdain and suspicion about too much effort going into their innovative teaching practices even though they were meeting other expectations for being granted tenure.

For Dr. Kelly :

"I've never had anybody say don't do that. Although you know with the globalization part I had a lot of chatter that said well you don't want to do that before you're promoted......It has a negative effect, the only reason you're doing that [global classroom effort] is because you can't do the other [research]. Yeah. I mean that's a real fear."

Dr. Donaldson $\mathrm{m}_{\mathrm{m}}$ was discouraged from going up for tenure based on excellence in teaching by the dean of the college. "No well he goes I will never in my time as dean recommend any one for 
tenure based on teaching." Even though Dr. Donaldson ${ }_{\mathrm{m}}$ was meeting the other expectations prior to tenure his commitment to teaching was still problematic

"So for me I looked at him and I felt like what I was doing I was meeting the expectations in what people wanted. It wasn't that I wasn't bringing in any research or I wasn't funding students. I mean I graduated 20 graduate students --20. I had a half a million dollars in external research funding."

In this environment, even participating in scholarship of teaching and learning activities was discouraged. Dr. Donaldson $\mathrm{m}_{\mathrm{m}}$ was co-authoring a paper for an engineering education conference with a colleague who had not come up for tenure and describes a conversation with this individual: "I know I shouldn't be writing this abstract and he was half joking and he was half for real too because where I came from educational conferences those types of stuff were not valued."

\section{Mixed Messages}

Both Dr. Donaldson $\mathrm{m}_{\mathrm{m}}$ and Dr. Kelly $\mathrm{y}_{1}$ reported mixed messages on the value of teaching from different levels of the university hierarchy. In his tenure process based on excellence in teaching Dr. Donaldson ${ }_{m}$ reported:

"Basically my department voted for tenure, the college level committee and the dean basically they kind of are hand in hand the college level committee voted not for tenure, the dean not for tenure but the university committee and the provost voted for tenure so it got over ruled and I got tenure from that. "

Dr. Kelly $y_{1}$ has received interest and recognition at the university wide level for his teaching innovations later in his career despite the negative "chatter" about his initiatives earlier in his career:

"I notice in this university you know outside of the department, people kind of respond positively to the kind of teaching things I've done. You know there is actually well they write more about it in public outlets you know."

Dr. Kelly ${ }_{1}$ goes on to explain:

"No question about it. You have mixed messages and what about the person who hasn't reached a point where they have something that can be written about when do they ever get the right message. I think a lot of people just drop out [of innovative teaching] before they ever get to that point."

\section{Discussion}

The individuals interviewed in this study managed to change and innovate with their teaching practices despite the environments that did not wholly support the efforts they focused on teaching. As assistant faculty two of these three individuals received messages that their innovative teaching practices were indicative of a lack of capability in research and publication. At the university level as established innovative teaching practitioners, they found support. Negative messages came from the department or college at early career stages. When asked why they persevered with their focus on innovative teaching both referred to themselves as stubborn and both appeared to have a sense of it being the right thing to do. All three of these faculty members identified an individual who aided them in their teaching evolution. These individuals served as mentors, provided someone to discuss changes in their teaching strategy, shared their 
passion for excellent teaching. These relationships were clearly important to them in their teaching journey.

Both Kelly $\mathrm{y}_{1}$ and Donaldson $\mathrm{m}_{\mathrm{m}}$ felt the most resistance to their adoption of innovative teaching methods while they were assistant professors. The traditional academic culture valorizes research over teaching, a fact most sharply brought into focus in the early stages of an academic's career. The pressures to conform in order to attain tenure can be overwhelming and it is unlikely that research universities will radically alter this attitude in the foreseeable future. Nevertheless, the need for change in the attitudes toward teaching in higher education exists.

The narrative teaching journeys related by these three innovative teachers suggest a few options where actions by funding organizations, professional societies, and university wide support structures might have a salutary impact. One would be the development of SOTL-related early career grants program analogous to NSF's prestigious CAREER awards programs supporting research development of early assistant professors. A second option would focus on nurturing teaching skills by requiring professional development courses at the graduate student level as part of the doctoral programs in engineering. While many colleges currently offer these courses, their presence within engineering colleges is still rare. Since the interviewees reported that colleagues and mentors enabled them to grow as teachers, a third option would be the instantiation of a network or mentoring infrastructure oriented specifically toward teaching by the university. A final option could target faculty teaching development programs toward associate professors, since the pressure for tenure is gone at that point in an academic career.

\section{References}

1. National Academy of Engineering. The Engineer of 2020: Visions of Engineering in the New Century. Washington, DC, 2004.

2. Rugarcia A, Felder RM, Woods DR, et al. The Future of Engineering Education I. A Vision for a New Century. Chemical Engineering Education 2000;34:16-25.

3. National Science Foundation. Shaping the Future: New Expectations for Undergraduate Education in Science, Mathematics, Engineering, and Technolog. Arlington, Virginia, 1996.

4. McKenna AF, Froyd JE, King CJ, et al. The Complexities of Transforming Engineering Higher Education: Report on Forum on Characterizing the Impact and Diffusion of Transformative Engineering Education Innovations. Washington, D.C.: Center for the Advancement of Scholarship on Engineering Education, National Academy of Engineering, 2011.

5. Froyd JE. Propagation and Realization of Educational Innovations in System of Undergraduate STEM Education: A White Paper Commission for the Characterizing the Impact of Diffusion of Engineering Education Innovations Forum, February 7-8, 2011. Washington, D.C.: Center for the Advancement of Scholarship on Engineering Education, National Academy of Engineer, 2010.

6. Henderson C, Dancy MH. Increasing the Impact and Diffusion of STEM Education Innovations: A White Paper commission for the Characterizing the Impact and 
Diffusion of Engineering Education Innovations Forum, Feb 7-8, 2011. Washington, DC: National Academy of Engineering, 2010.

7. Henderson C, Dancy MH. Barriers to the Use of Research-Based Instructional Strategies: The Influence of Both Individual and Situational Characteristics. Physical Review Special Topics - Physics Education Research 2007;3:020102-020101--020102-020114.

8. Henderson C, Dancy MH. Physics Faculty and Educational Researchers: Divergent Expectations as Barriers to the Diffusion of Innovations. American Journal of Physics 2008;76:79-91.

9. Hazen BT, Wu Y, Sankar CS. Factors That Influence Dissemination in Engineering Education. 2012.

10. Silva MK, Sheppard SD. Enabling and sustaining educational innovation, in ASEE Annual Conference Proceedings. 2001 ASEE Annual Conference and Exposition: Peppers, Papers, Pueblos and Professors, June 24, 2001 - June 27, 2001 2001;4155-4160.

11. Gustafson RJ. Determining impact of a course on teaching in engineering, in ASEE Annual Conference and Exposition, Conference Proceedings. 118th ASEE Annual Conference and Exposition, June 26, 2011 - June 29, 20112011.

12. Simon B, Bales E, Griswold WG, et al. Case study: Faculty professional development workshops for innovation diffusion, in SIGCSE'1 1 - Proceedings of the 42nd ACM Technical Symposium on Computer Science Education. 42nd ACM Technical Symposium on Computer Science Education, SIGCSE 2011, March 9, 2011 - March 12, 2011 2011;673-678.

13. Rogers EM. Diffusion of Innovations (5th edition). New York: Free Press, 2003.

14. Bandura A. Social Foundations of Thought and Action. Englewood Cliffs, N.J.: Prentice-Hall, 1986.

15. Kramp MK. Exploring Life and Experience Through Narrative Inquiry In: deMarrais K,Lapan SD, eds. Foundations for Research: Methods of Inquiry in Education and the Social Sciences. Mahwah, New Jersey: Lawrence Erlbaum Associates, 2004.

16. Labov W, Waletzky J. Narrative analysis: oral versions of personal experience In: Helm J, ed. Essays on the Verbal and Visual Arts. Seattle: University of Washington Press, 1967. 